ARTICLE

DOI: $10.1038 /$ s41467-018-05685-5

\title{
Influence of surface atomic structure demonstrated on oxygen incorporation mechanism at a model perovskite oxide
}

Michele Riva (10 1, Markus Kubicek², Xianfeng Hao ${ }^{3,4}$, Giada Franceschi', Stefan Gerhold ${ }^{1}$, Michael Schmid', Herbert Hutter ${ }^{2}$, Juergen Fleig (10 ${ }^{2}$, Cesare Franchini (i) ${ }^{4}$, Bilge Yildiz (i) ${ }^{1,5}$ \& Ulrike Diebold (1) ${ }^{1}$

Perovskite oxide surfaces catalyze oxygen exchange reactions that are crucial for fuel cells, electrolyzers, and thermochemical fuel synthesis. Here, by bridging the gap between surface analysis with atomic resolution and oxygen exchange kinetics measurements, we demonstrate how the exact surface atomic structure can determine the reactivity for oxygen exchange reactions on a model perovskite oxide. Two precisely controlled surface reconstructions with $(4 \times 1)$ and $(2 \times 5)$ symmetry on 0.5 wt.\% Nb-doped $\mathrm{SrTiO}_{3}(110)$ were subjected to isotopically labeled oxygen exchange at $450^{\circ} \mathrm{C}$. The oxygen incorporation rate is three times higher on the $(4 \times 1)$ surface phase compared to the $(2 \times 5)$. Common models of surface reactivity based on the availability of oxygen vacancies or on the ease of electron transfer cannot account for this difference. We propose a structure-driven oxygen exchange mechanism, relying on the flexibility of the surface coordination polyhedra that transform upon dissociation of oxygen molecules.

\footnotetext{
${ }^{1}$ Institute of Applied Physics, TU Wien, Wiedner Hauptstraße 8-10/E134, 1040 Wien, Austria. ${ }^{2}$ Institute of Chemical Technologies and Analytics, TU Wien, Getreidemarkt 9/164EC, 1060 Wien, Austria. ${ }^{3}$ Key Laboratory of Applied Chemistry, Department of Chemical Engineering, Yanshan University, 066004 Qinhuangdao, China. ${ }^{4}$ Faculty of Physics and Center for Computational Materials Science, University of Vienna, Sensengasse 8/8, 1090 Vienna, Austria. ${ }^{5}$ Laboratory for Electrochemical Interfaces, Departments of Nuclear Science and Engineering, and Materials Science and Engineering, Massachusetts Institute of Technology, 77 Massachusetts Avenue, Cambridge, MA 02139, USA. Correspondence and requests for materials should be addressed to B.Y. (email: byildiz@mit.edu) or to U.D. (email: diebold@iap.tuwien.ac.at)
} 
xygen reduction and oxygen evolution often limit the efficiency of energy conversion technologies including fuel cells, electrolyzers, and photo-/electrochemical water splitting. Perovskite oxides (of unit formula $\mathrm{ABO}_{3}$ ) are widely used and studied materials for enabling these reactions at elevated temperatures. They are used in solid oxide fuel cells (SOFC) for electricity production ${ }^{1-3}$, in the synthesis of fuels by electrolysis of water or steam ${ }^{4}$ and in the thermochemical splitting of water and $\mathrm{CO}_{2}{ }^{5}$. The reactivity on these perovskite oxides is often interpreted in terms of the availability of surface oxygen vacancies $\left(\mathrm{V}_{\mathrm{O}}\right)^{6-10}$ or electrons ${ }^{11-15}$ and the position of the oxygen $2 p$ band center $^{16}$. Undoubtedly, the atomic-scale details of surface structures ought to also be critical in determining the speed of the oxygen reduction and evolution reactions (ORR and OER), which is measured either electrochemically or by incorporation of isotopically labeled ${ }^{18} \mathrm{O}^{3,17,18}$. Intriguingly, none of these canonical reactivity models consider the role of the precise surface atomic structure. The important question is how the atomic configuration at the surface affects the ORR/OER mechanisms at the molecular level, either via these reactivity-determining factors or directly via the structure itself. For example, it was shown that $\mathrm{La}_{0.7} \mathrm{Sr}_{0.3} \mathrm{MnO}_{3}{ }^{19}, \mathrm{La}_{2} \mathrm{NiO}_{4}{ }^{20}, \mathrm{SrRuO}_{3}{ }^{21}$, and $\mathrm{SrTiO}_{3}{ }^{22}$ possess different oxygen exchange and water splitting kinetics depending on the surface crystallographic orientation, but the actual atomic structure of the surfaces was not resolved. Reliable computational modeling of surface reactivity at the first-principles level necessarily requires the geometric positions of the surface atoms as an input, which, in turn, need to be confirmed by experiments.

Knowing the geometric arrangement of the surface atoms under reaction conditions has been highly difficult, however. There are scarcely any methods that can determine the surface structure and measure the reactivity to oxygen exchange without perturbing the surface structure under reaction conditions of elevated temperatures and realistic reactant pressures. In addition, many of the Sr-doped perovskite oxides that are used in electrocatalytic or thermochemical reactions [e.g., $\mathrm{La}_{0.8} \mathrm{Sr}_{0.2} \mathrm{MnO}_{3}$ $(\mathrm{LSM})^{17}, \mathrm{La}_{0.6} \mathrm{Sr}_{0.4} \mathrm{CoO}_{3}$ (LSC) ${ }^{23}, \mathrm{La}_{0.6} \mathrm{Sr}_{0.4} \mathrm{Co}_{0.2} \mathrm{Fe}_{0.8} \mathrm{O}_{3}$ (LSCF) ${ }^{24}$, and $\left.\mathrm{Ba}_{0.5} \mathrm{Sr}_{0.5} \mathrm{Co}_{0.8} \mathrm{Fe}_{0.2} \mathrm{O}_{3} \quad(\mathrm{BSCF})^{25}\right]$ segregate out Sr-richinsulating phases ${ }^{26-30}$, and it is impossible to resolve these highly heterogeneous surface regions with atomic resolution.

In the present study, we marry physical surface science studies with kinetic oxygen exchange measurements on precisely controlled atomic structures and demonstrate how these affect oxygen exchange mechanisms and kinetics. We take $\mathrm{SrTiO}_{3}$ as a prototypical model perovskite oxide, primarily due to our ability to prepare $\mathrm{SrTiO}_{3}(110)$ with two distinctly different and controllable surface phases with solved structures ${ }^{31}$. Another advantage of this system is the fact that $\mathrm{Sr}$ segregation is suppressed if single-crystal $\mathrm{SrTiO}_{3}$ surfaces are stabilized by a reconstruction ${ }^{32}$. We use $0.5 \mathrm{wt} . \% \mathrm{Nb}$-doped samples that are sufficiently conductive for evaluating the atomic structure with STM. The relevant bulk $\mathrm{V}_{\mathrm{O}}$ concentration expected under the experimental conditions of this work is extremely low, as discussed later. The bulk oxygen transport is thus strongly suppressed, but the surface oxygen exchange reaction can still be probed in isotope exchange experiments. By quantifying the ${ }^{18} \mathrm{O}$ exchange for these two reconstructions, while keeping all other experimental parameters exactly constant, we find that their reactivity differs by a factor of three. Density functional theory (DFT) calculations on these precisely resolved surface structures reveal that this difference is neither related to oxygen vacancies nor to variations in work function or surface potential that would affect the availability of electrons on this material. Instead, the structural details determine the interaction with the molecular oxygen. Our results reveal the polyhedral flexibility up to the ideal coordination limit as an important and previously unexplored factor that can govern the reactivity to oxygen exchange reactions on perovskite oxides surfaces.

\section{Results}

Characterization of $\mathrm{SrTiO}_{3}(110)$ surface reconstructions. Figure 1 shows the $(4 \times 1)$ - and $(2 \times 5)$-reconstructed surfaces of $\mathrm{SrTiO}_{3}(110)$, prepared as described in the "Methods" section. In both cases, a layer of $\mathrm{TiO}_{x}$ polyhedra $(x=4,5,6$ as defined below) sits on a $(\mathrm{SrTiO})^{4+}$ plane, which is only marginally distorted from its bulk structure. These top titania overlayers have distinctly different structural properties, however. The $(4 \times 1)$ surface (Fig. 1a) consists of a porous network of corner-sharing tetrahedrally coordinated $\mathrm{TiO}_{4}$ units, arranged into six- and tenmembered rings (highlighted by tetrahedra in Fig. 1a). The $\mathrm{SrTiO}_{3}(110)-(2 \times 5)$-reconstructed surface (Fig. 1b) consists, instead, of a bilayer of octahedrally coordinated $\mathrm{Ti}$ atoms. The subsurface layer consists of edge- and corner-sharing octahedra. The topmost surface layer hosts 16 edge-sharing $\mathrm{TiO}_{6}$ octahedra,
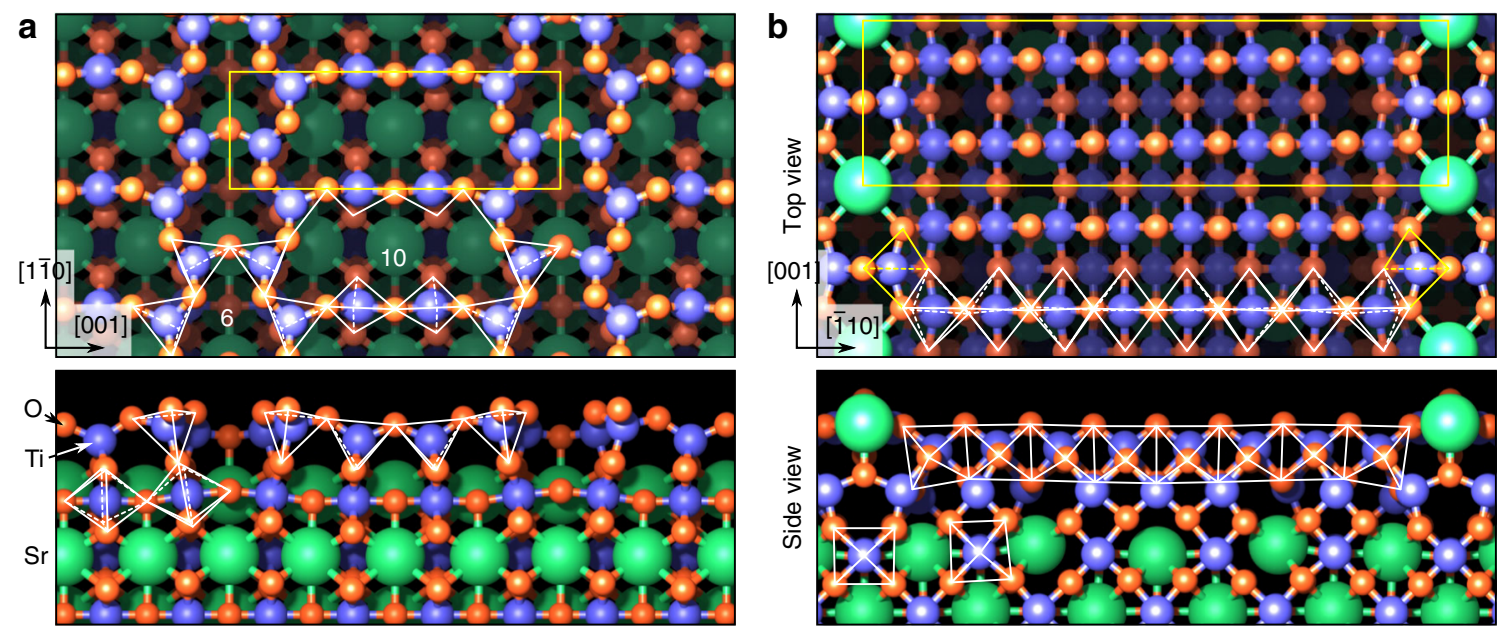

Fig. 1 Surface structure models on $\mathrm{SrTiO}_{3}(110)$. a $\mathrm{SrTiO}_{3}(110)-(4 \times 1)$, and $\mathbf{b} \mathrm{SrTiO}_{3}(110)-(2 \times 5)$ surface reconstructions ${ }^{31}$. Top view (top) and crosssection view (bottom). Notice that the structures are displayed with a $90^{\circ}$ in-plane rotation. $\mathrm{Ti}, \mathrm{Sr}$, and $\mathrm{O}$ atoms are drawn as blue, green, and red spheres, respectively. The Ti coordination polyhedra are represented by white lines. While the $(4 \times 1)$ surface $(\mathbf{a})$ is composed of ten- and six-membered rings of corner-sharing tetrahedra, the $(2 \times 5)$ surface $(\mathbf{b})$ consists of a bilayer of octahedra 

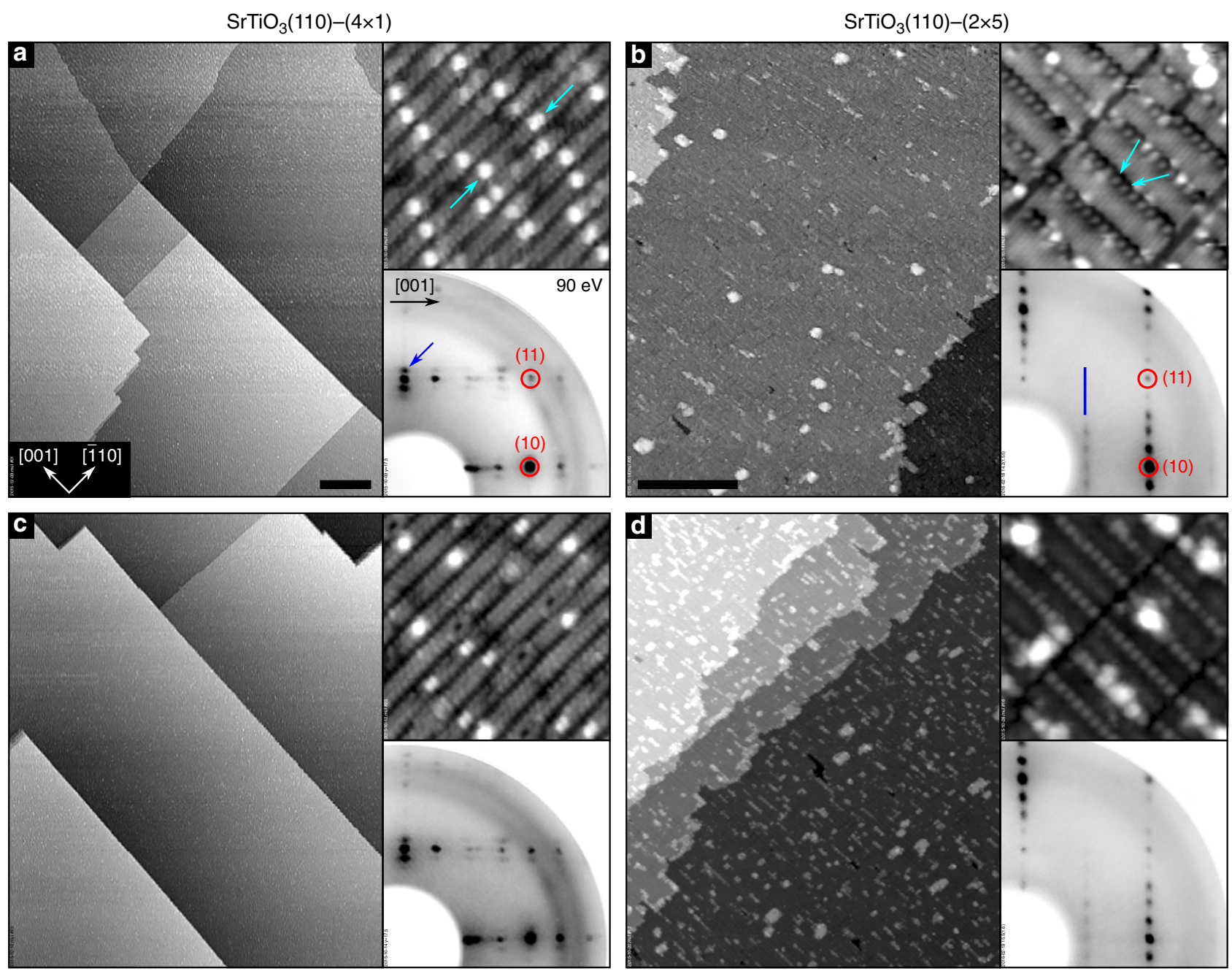

Fig. 2 Surface structures of $\mathrm{SrTiO}_{3}(110)$, and their stability upon treatment in oxygen atmosphere. Scanning tunneling microscopy (STM) images (main panels: a, c $410 \times 500 \mathrm{~nm}^{2}$; b, d $190 \times 230 \mathrm{~nm}^{2}$; scale bars represent a length of $50 \mathrm{~nm}$; top-right insets: $15 \times 15 \mathrm{~nm}^{2}$ ), and LEED patterns of the $\mathrm{SrTiO}_{3}(110)-(4 \times 1)(\mathbf{a}, \mathbf{c})$ and $-(2 \times 5)(\mathbf{b}, \mathbf{d})$ surfaces. The as-prepared $(\mathbf{a}, \mathbf{b})$ and $\mathrm{O}_{2}$-annealed $(\mathbf{c}, \mathbf{d})$ samples appear similar; the slightly different contrast observed in the high-resolution STM images of $\mathbf{b}$ and $\mathbf{d}$ are related to variations of the tip termination

and two $\mathrm{TiO}_{5}$ units, in which the apical oxygen atom is missing. Finally, fivefold-coordinated $\mathrm{Sr}$ atoms alternate with the $\mathrm{TiO}_{5}$ units, with a twofold periodicity along [001]. Similar to other surfaces of $\mathrm{SrTiO}_{3}{ }^{33}$, these reconstructions on n-type $\mathrm{SrTiO}_{3}(110)$ form due to thermodynamic conditions, and in this case mainly due to the minimization of surface energy ${ }^{31}$ as a function of chemical potential of $\mathrm{Ti}$ and $\mathrm{Sr}$, and of strain energy ${ }^{34}$. The same reconstructions exist on undoped or p-type-doped $\mathrm{SrTiO}_{3}(110)$ surfaces.

Representative scanning tunneling microscopy (STM) images and low-energy electron diffraction (LEED) patterns from these two surfaces are shown in Fig. 2. The six- and ten-membered rings of $\mathrm{TiO}_{4}$ on the $(4 \times 1)$ surface give rise to rows running along the $[1 \overline{1} 0]$ direction, separated by darker trenches along [001], as seen in the high-resolution STM images. Bright, isolated features (light-blue arrows in the top-right inset of Fig. 2a) have been identified as single $\mathrm{Sr}$ adatoms, preferentially occupying a surface domain boundary ${ }^{34}$. In wide-area STM images, $(4 \times 1)$-reconstructed $\mathrm{SrTiO}_{3}(110)$ surfaces exhibit large (20-300 nm), atomically flat terraces, separated by steps with single $(275 \mathrm{pm})$ or multiple unit-cell heights, preferentially running along low-index directions (see main panel of Fig. 2a). On the $(2 \times 5)$ surface, $\mathrm{Sr}$ atoms close to the $\mathrm{TiO}_{5}$ units are usually predominantly visible in high-resolution STM (indicated by the light-blue arrows in Fig. 2b). These $\mathrm{Sr}$ atoms are imaged as protrusions centered on shallow dark trenches, while the surface $\mathrm{TiO}_{6}$ octahedra are responsible for the bright appearance of the stripes extending along the [001] direction ${ }^{31}$. The inset shows the characteristic LEED pattern with $(2 \times 5)$ periodicity. In large-area STM images, the $(2 \times 5)$-reconstructed $\mathrm{SrTiO}_{3}(110)$ surface shows flat terraces with a morphology similar to the $(4 \times 1)$ reconstruction.

After annealing these samples in oxygen atmosphere prior to the ${ }^{18} \mathrm{O}$ exchange experiment $\left(450^{\circ} \mathrm{C}, 0.1 \mathrm{mbar} \mathrm{O}_{2}\right.$, for $\left.5 \mathrm{~h}\right)$, the atomic-scale structure appears essentially unchanged for both surfaces, seen from comparing Fig. 2a, b with Fig. $2 c$, d. The $(4 \times 1)$-reconstructed surface (Fig. 2 c) retains the atomically flat, large-scale morphology of the pristine sample. On the $\mathrm{SrTiO}_{3}(110)-(2 \times 5)$ surface (Fig. 2d), the morphology is also largely preserved, along with a slight increase of the fraction covered by rectangular islands. It is known that even small changes in the surface $\mathrm{Ti} / \mathrm{Sr}$ ratio would switch the surface to another reconstruction ${ }^{35}$, thus we can exclude any cation segregation. These surface structures are stable upon annealing under the same conditions for a total of $20 \mathrm{~h}$, see Supplementary Fig. 2.

We also prepared a "surface bi-crystal," i.e., a sample with zones of $(4 \times 1)$ and $(2 \times 5)$ surface structures. The bulk of the 
a

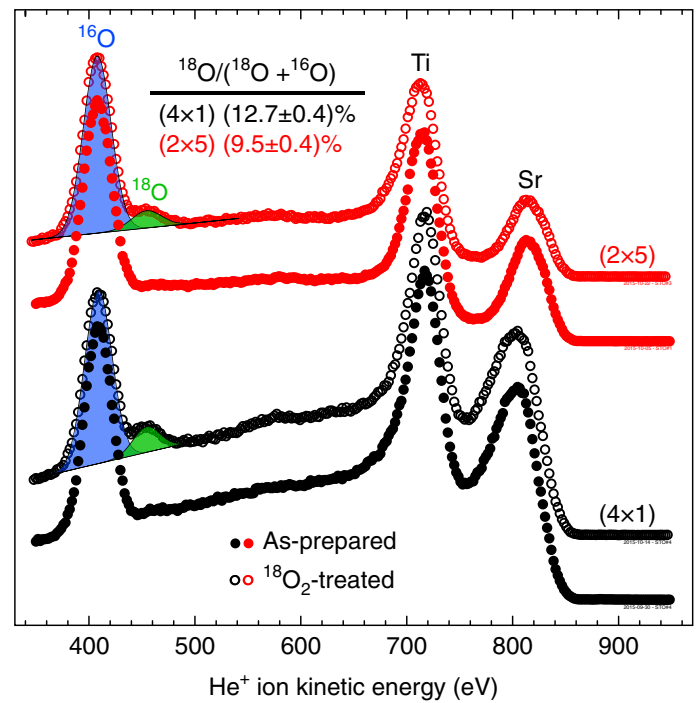

b

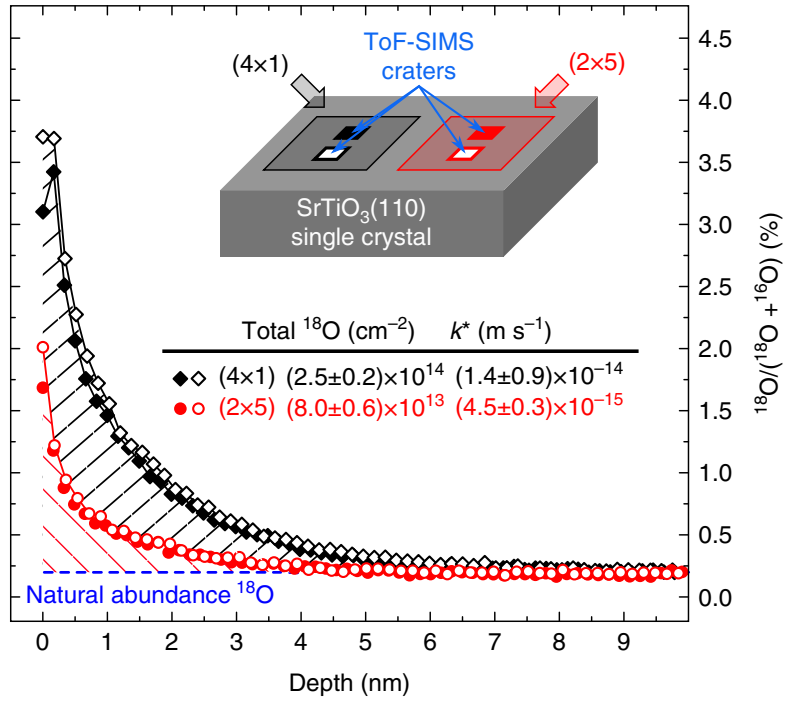

Fig. 3 Oxygen-isotope-sensitive ion spectroscopy measurements performed on the $\mathrm{SrTiO}_{3}(110)$-reconstructed surfaces. a LEIS spectra (He ${ }^{+}$with 1000 eV primary energy) measured on $(4 \times 1)$ - (black), and $(2 \times 5)$-reconstructed (red) $\mathrm{SrTiO}_{3}(110)$ surfaces, respectively. Results from as-prepared and ${ }^{18} \mathrm{O}$-exchanged samples are displayed with full and open symbols, respectively. Each spectrum is normalized to the total $\mathrm{O}$ signal. The uncertainty (standard error) on the fractional ${ }^{18} \mathrm{O}$ signals reported in the table is $0.4 \%$ for both surfaces. $\mathbf{b}$ ToF-SIMS ${ }^{18} \mathrm{O}$ isotope exchange depth profiles measured on $(4 \times 1)$ - (black), and (2×5)-reconstructed (red) $\mathrm{SrTiO}_{3}(110)$ surfaces of the same crystal. Here, open and full symbols correspond to two separate measurements on different spots on each half of the bi-crystal

material has thus exactly the same sample history and composition, only the surfaces are different. Sample work functions were determined by measuring the cutoff of secondary electrons (excited by X-rays); the values are $4.470(3) \mathrm{eV}$ and $4.051(10) \mathrm{eV}$ for the $(4 \times 1)$ and $(2 \times 5)$ reconstructions, respectively (data shown in Supplementary Fig. 5). By comparing the core-level energies in X-ray photoelectron spectra (XPS) of the two zones on the surface bi-crystal (see Supplementary Fig. 6), no difference in band bending was found, indicating that any surface potential difference is negligible within the measurement uncertainty $( \pm 0.03 \mathrm{eV})$.

${ }^{18} \mathrm{O}_{2}$ exchange kinetics from ion spectroscopies. ${ }^{18} \mathrm{O}$ exchange was conducted on monophase samples and on the surface bicrystal sample. The resulting tracer incorporation was evaluated with secondary ion mass spectrometry (SIMS) and low-energy $\mathrm{He}^{+}$ion scattering (LEIS), see Fig. 3. The LEIS spectra were acquired on the monophase samples in ultra-high vacuum (UHV) right after the ${ }^{18} \mathrm{O}$ treatment (Fig. 3a). Figure $3 \mathrm{~b}$ shows representative SIMS depth profiles for the ${ }^{18} \mathrm{O}$ isotope on the different zones of the surface bi-crystal; similar results were achieved for the monophase samples (Supplementary Fig. 1). In each case, the $(4 \times 1)$-reconstructed surface incorporates significantly more ${ }^{18} \mathrm{O}$ during the exchange process than the $(2 \times 5)$ reconstructed surface.

Quantification of tracer incorporation at the surface is commonly assessed through the determination of the exchange coefficient $k^{\star}$. This is usually accomplished by fitting the measured tracer fraction profile to analytical or numerical solutions of Fick's law of diffusion. However, this approach is not applicable in our case, since the profiles in Fig. $3 \mathrm{~b}$ are extremely shallow due to virtual absence of oxygen vacancies in the bulk of donor-doped $\mathrm{SrTiO}_{3}$ (Supplementary Note 6), and are dominated by SIMS-related broadening effects (see Supplementary Note 3 and Supplementary Fig. 4). The total amount of incorporated ${ }^{18} \mathrm{O}$, however, can still be correctly determined by integration of the ${ }^{18} \mathrm{O}$ profiles (see Fig. 3b). From this total amount of exchanged ${ }^{18} \mathrm{O}$, an oxygen exchange rate coefficient $k^{\star}$ can be obtained (see Methods and Supplementary Eqs. (1-5)). With exchange times of $1 \mathrm{~h}$ and $4 \mathrm{~h}$, we find $k^{\star}$ to be $4.5-6.0 \times 10^{-15} \mathrm{~m} \mathrm{~s}^{-1}$ for the $(2 \times 5)$-reconstructed surface, and approximately three times as much $\left(1.4-1.8 \times 10^{-14} \mathrm{~m} \mathrm{~s}^{-1}\right)$ for the $(4 \times 1)$ (Fig. 3 and Supplementary Fig. 3). Moreover, the ratio of effective surface exchange constants $k_{(4 \times 1)}^{*} / k_{(2 \times 5)}^{*}$ amounts to $3.1 \pm 0.3$ and $3.1 \pm 0.6$ for the $1 \mathrm{~h}$ and $4 \mathrm{~h}$ annealing periods, respectively, implying that the incorporation via the surface remains constant over time, at least over several hours. We can thereby exclude that either saturation effects, or different transport in the near-surface regions are responsible for the observed differences between the two reconstructions. Consequently, only the different activity of the respective surface structures is responsible for the threefold larger ${ }^{18} \mathrm{O}$ incorporation on the $(4 \times 1)$.

It has to be noted that, with respect to LEIS (Fig. 3b), SIMS (Fig. 3a) measures a larger difference in incorporated oxygen between $(4 \times 1)$ and $(2 \times 5)$. The reason lies in the different probing depths of the two techniques: While SIMS probes the total amount of tracer ions incorporated in the samples, LEIS is strictly surface sensitive, and therefore probes the ${ }^{18} \mathrm{O}$ density in the topmost surface layer only. This surface ${ }^{18} \mathrm{O}$ density is obtained by scaling the LEIS-measured tracer concentrations with the corresponding density of oxygen atoms in the topmost layer $\left[8.81 \times 10^{14} \mathrm{~cm}^{-2}\right.$ and $1.04 \times 10^{15} \mathrm{~cm}^{-2}$ for $(2 \times 5)$ and $(4 \times 1)$, respectively], and amounts to $(8.4 \pm 0.4) \times 10^{13} \mathrm{~cm}^{-2}$ for $(2 \times 5)$ and to $(1.33 \pm 0.04) \times 10^{14} \mathrm{~cm}^{-2}$ for $(4 \times 1)$. The ${ }^{18} \mathrm{O}$ density on the $(2 \times 5)$ surface nicely agrees with the total SIMS signal $[(8.0 \pm$ $\left.0.6) \times 10^{13} \mathrm{~cm}^{-2}\right]$, whereas on $(4 \times 1)$ it amounts to half of the total SIMS counts $\left[(2.5 \pm 0.2) \times 10^{14} \mathrm{~cm}^{-2}\right]$. This strongly suggests that oxygen exchange is confined to the topmost surface layer on the $(2 \times 5)$, while on the $(4 \times 1)$ a few atomic layers are involved. This argument is further strengthened by DFT calculations (see below), which show that oxygen vacancies are more prevalent at the very surface on the $(2 \times 5)$, while subsurface sites are favored on the $(4 \times 1)$. Moreover, the slight broadening 
Time (ps)
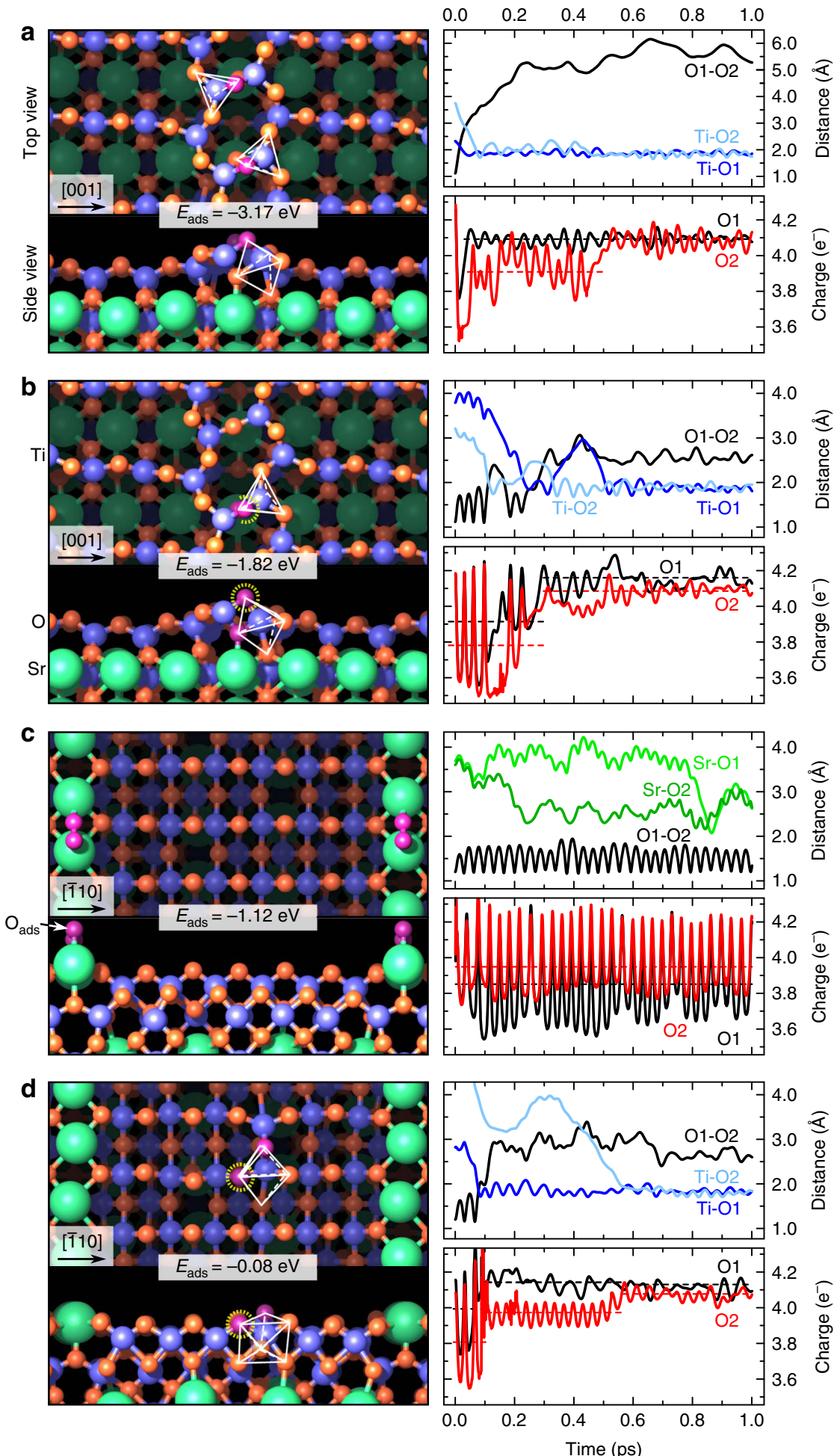

Fig. $4 \mathrm{O}_{2}$ adsorption structures and $\mathrm{O}_{2}$ dynamics calculated by FPMD-DFT. Lowest-energy structural models and time evolution (first 1.0 ps; for later time the results remain unchanged) of selected ionic distances and charge populations during the adsorption of one $\mathrm{O}_{2}$ on $\mathbf{a}$ the $(n \times 1)$ and $\mathbf{c}$ the $(2 \times n)$ surfaces without a vacancy, and on $\mathbf{b}$ the $(n \times 1)$ and $\mathbf{d}$ the $(2 \times n)$ surfaces with one $\mathrm{V}_{\mathrm{O}}$ (the $\mathrm{O}$ atom filling the $\mathrm{V}_{\mathrm{O}}$ is highlighted with a dashed yellow circle). Adsorption energies are indicated, and take into account also the $\mathrm{V}_{\mathrm{O}}$ formation energy. Green, red, and blue spheres indicate $\mathrm{Sr}$, $\mathrm{O}$, and $\mathrm{Ti}$ atoms, respectively. The intact, adsorbed $\mathrm{O}_{2}$ molecule and the $\mathrm{O}$ atoms resulting from its dissociation are depicted in purple. Five- (a, b) and sevenfold (d) coordination polyhedra of $\mathrm{Ti}$ are outlined in white. $\mathrm{O} 1$ and $\mathrm{O} 2$ refer to the oxygen atoms belonging to the $\mathrm{O}_{2}$ molecule, while $\mathrm{Ti}-\mathrm{O} 1$ ( $\mathrm{Ti}-\mathrm{O} 2$ ) is the distance between $\mathrm{O} 1(\mathrm{O} 2)$ and the closest $\mathrm{Ti}$ atom in the structure 
of the SIMS profile found for $(4 \times 1)$ after long exchange time (see Supplementary Note 3 ) supports this conclusion.

$\mathrm{O}_{2}$ reactivity from DFT calculations. The availability of wellsupported atomic surface models ${ }^{31,34,35}$ (Fig. 1) and the fact that these structures are not affected by annealing in ${ }^{18} \mathrm{O}_{2}$ (Fig. 2) allow us to directly relate the experimental results to firstprinciples calculations. We first evaluated the formation energies for $\mathrm{O}$ vacancies at various positions within the reconstruction layer, both on the top of the surface and closer to the interface with the underlying $\mathrm{SrTiO}_{3}$ bulk lattice (Supplementary Fig. 7 and Supplementary Table 1). The formation of the lowest-energy $V_{O}$ on the $(2 \times 5)$ surface layer is more favorable by $2.2 \mathrm{eV}$ than on the $(4 \times 1)$ surface. Thus, ease of surface $V_{O}$ formation is clearly not a decisive factor in the ${ }^{18} \mathrm{O}$ exchange.

Next, we modeled with first-principles molecular dynamics (FPMD) the interaction of $\mathrm{O}_{2}$ considering a vacancy-free surface and a defective one with a single $V_{O}$ for each of the two reconstructions. The adsorption structures with the lowest energy at the end of the FPMD runs are displayed in Fig. 4, along with the corresponding relative adsorption energies $E_{\text {ads. }}$. These structures are thermodynamically stable, as proven by the phase diagram shown in Supplementary Figs. 11 and 12. Additional (less stable) configurations are shown in Supplementary Fig. 8 and Supplementary Table 2. The kinetics of the entire process of oxygen incorporation depends on the adsorption energies as well as the unit reaction energy barriers. The rate of incorporation of oxygen from surface to subsurface is affected by the concentration of adsorbed oxygen at the surface. That term, the source of oxygen incorporation, is determined by adsorption energies. For the vacancy-free surfaces, $\mathrm{O}_{2}$ dissociative adsorption/incorporation is considerably more favorable in the $(4 \times 1)$ structure. Even without a $\mathrm{V}_{\mathrm{O}}, \mathrm{O}_{2}$ easily dissociates and incorporates into the $(4 \times 1)$ surface at both the six-member and the ten-member rings of $\mathrm{TiO}_{4}$ tetrahedra, with an energy gain of $-3.17 \mathrm{eV}$ and -2.94 $\mathrm{eV}$, respectively. On the vacancy-free $(2 \times 5)$ surface, in contrast, $\mathrm{O}_{2}$ does not dissociate. It stays anchored on top of the Sr rows (see Fig. 4c). $\mathrm{O}_{2}$ adsorption and dissociation is also energetically highly unfavorable on the flat $\mathrm{TiO}_{6}$ area, resulting in a positive adsorption energy (see Supplementary Fig. 8). If $\mathrm{V}_{\mathrm{O}} \mathrm{s}$ are present in the $(2 \times 5)$ structure, they play the role of an active center for $\mathrm{O}_{2}$ dissociation (see Fig. 4d): one $\mathrm{O}$ fills the $\mathrm{V}_{\mathrm{O}}$ site, whereas the second one hops into a nearby bridge position between two surface $\mathrm{Ti}$ atoms. We note here that it is important to consider and compare these adsorption energies in the kinetics of oxygen incorporation.

These results can be rationalized by inspecting the time evolution of the relevant ionic distances and the $\mathrm{O}_{2}$ valence charge during the dissociation of the $\mathrm{O}_{2}$ molecule in the $(4 \times 1)$ and $(2 \times 5)$ surfaces without and with vacancy ${ }^{36}$, see Fig. 4 . In the $(4 \times 1)$ phase, the $\mathrm{O} 1-\mathrm{O} 2$ bond of the $\mathrm{O}_{2}$ molecule breaks rapidly during the initial $0.3 \mathrm{ps}$, and the $\mathrm{O} 1 / \mathrm{O} 2$ valence charges increase by about 0.3 electrons as a result of charge transfer from the surface Ti atoms. The $\mathrm{O}_{2}$ dissociation mechanism in the vacancyfree $(4 \times 1)$ surface is different compared to the defective surface. Without $\mathrm{V}_{\mathrm{O}}$ the dissociated $\mathrm{O}$ atoms bind to surface Ti atoms located on opposite sides of the six-member ring, as confirmed by the increasing $\mathrm{O} 1-\mathrm{O} 2$ distance and the decrease of the $\mathrm{Ti}-\mathrm{O}$ distances. Instead, on the defective surface, one $\mathrm{O}$ atom remains at the surface filling the $\mathrm{V}_{\mathrm{O}}$ site and re-establishing the Ti-O bond, while the second one is incorporated in the subsurface, increasing the coordination of the $\mathrm{Ti}$ atoms from $\mathrm{TiO}_{4}$ to $\mathrm{TiO}_{5}$. The overall energy gain, $-1.82 \mathrm{eV}$, is reduced by about $1.3 \mathrm{eV}$ with respect to the vacancy-free surface due to the large energy cost to form $\mathrm{V}_{\mathrm{O}}$ s (see Supplementary Table 1). A similar

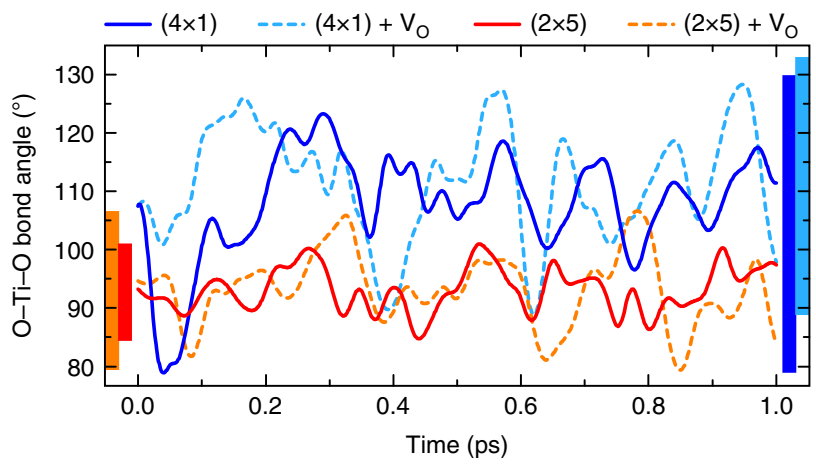

Fig. 5 Dynamical reorganization of the $\mathrm{TiO}_{4}$ and $\mathrm{TiO}_{6}$ polyhedra. Time evolution of the average $\mathrm{O}-\mathrm{Ti}-\mathrm{O}$ angle in the $(4 \times 1)$ and $(2 \times 5)$ surfaces with and without oxygen vacancy. Trajectories are shown during the first $1.0 \mathrm{ps}$, but qualitatively similar results are obtained for the whole time range considered in the calculation (10 ps). Vertical bars indicate the maximum amplitude of the oscillations during the whole simulation period

dissociation mechanism is at play on the defective $(2 \times 5)$ surface (Fig. 4d) but the final energy gain is much smaller-by $1.74 \mathrm{eV}-$ compared to $(4 \times 1)$. Conversely, on the vacancy-free $(2 \times 5)$ surface, the $\mathrm{O} 1-\mathrm{O} 2$ bond does not break (the bond length oscillates between $1.2 \AA$ and $1.6 \AA$ ), and the $\mathrm{O}_{2}$ molecule binds weakly to the underlying $\mathrm{Sr}$ atoms.

We have also computed the activation energy for the $\mathrm{O}_{2}$ dissociation process on both surfaces with nudged elastic band (NEB) calculations. Since $\mathrm{O}_{2}$ dissociation is endothermic on the vacancy free $(2 \times 5)$ (Supplementary Fig. 8 ), we have only considered the vacancy-free $(4 \times 1)$ and both the $(4 \times 1)$ and $(2 \times 5)$ surfaces with one $V_{O}$. The results, collected in Supplementary Fig. 9, deliver low transition barriers: $0.3 \mathrm{eV}$ for the clean and defective $(4 \times 1)$, and $0.1 \mathrm{eV}$ for the defective $(2 \times 5)$ reconstruction.

We attribute the different reactivity of the $(4 \times 1)$ and $(2 \times 5)$ surfaces to the different degree of structural flexibility of the $\mathrm{TiO}_{4}$ and $\mathrm{TiO}_{6}$ surface polyhedra, manifested by the dynamical structural reorganization (rotations and distortions associated with phonon softening, see Supplementary Note 10 and ref. ${ }^{37}$ ) of the $\mathrm{TiO}_{4}$ and $\mathrm{TiO}_{6}$ units during the adsorption process. The time evolution of the average $\mathrm{O}-\mathrm{Ti}-\mathrm{O}$ angle of surface polyhedra in the $(4 \times 1)$ and $(2 \times 5)$ surfaces, displayed in Fig. 5 , shows that the under-coordinated $\mathrm{TiO}_{4}$ polyhedra undergo much larger oscillations compared to the $\mathrm{TiO}_{6}$ units. The ease of performing such structural distortions ultimately provides the $(4 \times 1)$ surface with the structural flexibility to host external adsorbates such as $\mathrm{O}_{2}$, and off-stoichiometry facilitates charge transfer from the undercoordinated $\mathrm{Ti}$ atoms to the adsorbed oxygen. In contrast, stoichiometric $\mathrm{TiO}_{6}$ octahedra are structurally rigid and chemically saturated, and active adsorption and migration is reduced or suppressed, unless oxygen vacancies that reduce the $\mathrm{TiO}_{6}$ coordination are formed. In other words, such dynamic reorganization performs similarly to a mobile oxygen vacancy at the surface, and represents an alternative way to promote the oxygen incorporation reaction.

\section{Discussion}

Our experimental and computational results are at odds with the commonly accepted models for oxygen exchange mentioned above, i.e., availability and mobility of $\mathrm{V}_{\mathrm{O}} \mathrm{s}^{6-10}$ and the electronic effects that facilitate electron transfer ${ }^{11-14}$. Our experimental and theoretical methods allow us to independently assess these factors: their values suggest a higher reactivity of the $(2 \times 5)$ structure, the opposite of what is observed in the ${ }^{18} \mathrm{O}$ experiments. 
From our DFT calculations (Supplementary Fig. 7 and Supplementary Table 1$)$, the $(2 \times 5)$ surface should accommodate a larger concentration of oxygen vacancies at the surface compared to $(4 \times 1)$. The preferential vacancy formation sites on the $(4 \times 1)$ system are, in fact, sub-surface ${ }^{38}$. Therefore, the vacancy mechanism cannot explain the higher reactivity of the $(4 \times 1)$ compared to the $(2 \times 5)$ surface. When it comes to the ease of electron transfer, the surface work function is a good measure to correlate to reactivity ${ }^{1-14}$. The work function measured by XPS and calculated by DFT is lower by $0.42 \mathrm{eV}$ and $0.7 \mathrm{eV}$, respectively, for the $(2 \times 5)$ compared to the $(4 \times 1)$ surface. The corelevel binding energies measured on the $(4 \times 1)$ and the $(2 \times 5)$ surfaces are the same (Supplementary Fig. 6). Therefore, the surface potential or band bending (if it exists) is the same on these two surfaces, and the vacuum level on the $(2 \times 5)$ surface should be lower. In addition, the $(4 \times 1)$ surface has a larger band gap than the $(2 \times 5)^{38}$. Therefore, electron transfer to $\mathrm{O}_{2}$ molecules should be easier at the $(2 \times 5)$ surface. Again, this cannot explain why $(4 \times 1)$ is more reactive. In addition, from our STM images it is clear that the step density, which can significantly enhance reactivity ${ }^{39}$, is comparable on both surfaces, or slightly higher at the $(2 \times 5)$ surface after oxygen exchange treatment (Fig. 2$)$. Thus, step density cannot be the reason for the higher reactivity of the $(4 \times 1)$ either. Consequently, none of these traditionally considered models related to vacancies, electronic structure, or step edges for controlling the reactivity of oxide surfaces are able to explain the difference found between the reactivities of the $(4 \times 1)$ - and $(2 \times 5)$-reconstructed surfaces on $\mathrm{SrTiO}_{3}(110)$.

Our computational results reveal that oxygen incorporation on $\mathrm{SrTiO}_{3}(110)$ is affected directly via the atomic structure itself. The lower coordination of $\mathrm{Ti}$ by $\mathrm{O}$ atoms on the $(4 \times 1)$ accommodates the adsorbed/dissociated oxygen by increasing the coordination of $\mathrm{Ti}$, either at the top surface or by incorporating oxygen atoms to the first subsurface layer. In other words, the enhanced reactivity of the $(4 \times 1)$ toward $\mathrm{O}_{2}$ dissociative adsorption and incorporation is a result of the increased degree of structural and chemical flexibility of the under-coordinated $\mathrm{TiO}_{4}$ units as compared to the almost fully coordinated and rigid $\mathrm{TiO}_{5}$ and $\mathrm{TiO}_{6}$ units in the $(2 \times 5)$. The rigid $\mathrm{TiO}_{6}$ polyhedra in the $(2 \times 5)$ surface cannot accommodate more oxygen unless surface $\mathrm{V}_{\mathrm{O}} \mathrm{s}$ assist the reaction.

Thus, we suggest that two parallel oxygen exchange mechanisms are present on our $\mathrm{SrTiO}_{3}$ surfaces: a structurally mediated mechanism, dominating the exchange rate on the $(4 \times 1)$ surface, and a vacancy-mediated one, enabling exchange also on the $(2 \times 5)$ surface.

Existence of a vacancy-mediated oxygen exchange is often assumed in the literature, and the oxygen exchange rate is frequently compared with the (bulk) $\mathrm{V}_{\mathrm{O}}$ concentration $^{6}$. A direct and proportional dependence of the $k^{*}$ on the oxygen vacancy concentration in the bulk was shown for some perovskite oxides 6 . $k^{*}$ divided by the fraction of oxygen sites occupied by $\mathrm{V}_{\mathrm{O}}$, denoted here as $k_{\mathrm{V}}^{\star}$, amounts to $10^{-6} \mathrm{~m} \mathrm{~s}^{-1}$ and $10^{-5} \mathrm{~m} \mathrm{~s}^{-1}$ for LSCF and BSCF, respectively, at $800^{\circ} \mathrm{C}$ in air $^{6}$, and to $10^{-9}-10^{-8}$ $\mathrm{m} \mathrm{s}^{-1}$ for LSC at $450^{\circ} \mathrm{C}$ and $200 \mathrm{mbar} \mathrm{O}_{2}{ }^{40}$. On $(2 \times 5)$-reconstructed surfaces of our $0.5 \mathrm{wt} . \% \mathrm{Nb}$-doped $\mathrm{SrTiO}_{3}(110), k_{\mathrm{V}}^{\star}$ is at least on the order of $10^{-4} \mathrm{~m} \mathrm{~s}^{-1}$ at $450^{\circ} \mathrm{C}$ and 0.1 mbar oxygen (see Supplementary Note 6 for estimates of the vacancy concentration in our samples). Intriguingly, this value is comparable to that on LSCF and BSCF, and several orders of magnitude higher than the values reported for LSC. A possible factor contributing to this large discrepancy is the completely clean and stable atomic structures that are retained without any segregation of cations, impurities, or secondary phases on our samples. The often-found surface segregation and phase precipitation of $\mathrm{SrO}_{x}$ or impurities on the aliovalently doped systems hinder their surface reactivity by blocking the electron and oxygen transfer reactions ${ }^{30,41,42}$. Indeed, a substantially enhanced $k^{\star}$ was found for a clean LSC surface upon removal of the $\mathrm{SrO}_{x}$ termination layer ${ }^{43}$. Presumably, for vacancy-rich perovskite oxides the full potential of oxygen activity has not been exploited yet. These findings further demonstrate that establishing physics-based relations of the very surface state to the reaction kinetics is needed for a mechanistic understanding, rather than relying only on bulk non-stoichiometry of oxygen as a descriptor.

In summary, we have realized a comprehensive and gapbridging approach between model surfaces with well-defined atomic structure and macroscopic kinetic measurements of reaction rates, and revealed a dependence of reactivity on the precise surface atomic structure on a perovskite oxide. The oxygen exchange kinetics is three times faster on the $(4 \times 1)$-reconstructed surface of $\mathrm{SrTiO}_{3}(110)$ than on the $(2 \times 5)$ one. Neither availability of surface vacancies nor the work function or band bending can explain this enhanced reactivity of the $(4 \times 1)$ surface. We find that the surface atomic structure itself has the dominant role by assisting the oxygen adsorption and dissociation on the $(4 \times 1)$ surface, owing to a high degree of dynamical flexibility of the under-coordinated surface Ti atoms. This directly demonstrates and explains the influence of reconstructions on the reactivity of a perovskite oxide. Reconstructions are prevalent at the surfaces of any complex oxide ${ }^{44}$, and oxides with other transition metal cations such as $\mathrm{Fe}, \mathrm{Mn}$, and Co can as well form different polyhedral coordinations ${ }^{45,46}$. Accordingly, the higher flexibility of unsaturated metal-oxygen polyhedra may play a role in affecting the ease of oxygen incorporation on a broader range of perovskite oxide surfaces. Most importantly, the gap-bridging approach that we demonstrated here should motivate more research in resolving the surface atomic structure and relating that to reactivity on a wider range of perovskite oxides.

\section{Methods}

Sample preparation. The surfaces of one-side polished, Nb-doped ( $0.5 \mathrm{wt} . \%)$ $\mathrm{SrTiO}_{3}(110)$ single crystals $\left(5 \times 5 \mathrm{~mm}^{2}\right.$, Crystec $\left.\mathrm{GmbH}\right)$ were prepared in an ultrahigh vacuum (UHV) system ${ }^{47}$. The latter is composed of three in situ interconnected vessels: The preparation chamber is used for Ar-ion sputtering, electronbeam annealing, and contains molecular beam epitaxy (MBE) facilities. The analysis chamber houses a low-energy electron diffraction (LEED) setup, a hemispherical analyzer for X-ray photoelectron (XPS) and low-energy ion scattering (LEIS; $1 \mathrm{keV} \mathrm{He}^{+}$; scattering angle $132^{\circ}$ ) spectroscopies, and a variabletemperature scanning tunneling microscope (STM). The oxygen exchange experiments were performed in the third vessel (pulsed laser deposition chamber), allowing for infrared-laser annealing of samples at elevated oxygen pressures (up to 200 mbar)

The $\mathrm{SrTiO}_{3}(110)$ crystals were cleaned in the preparation chamber by repeated cycles of sputtering $(1 \mathrm{keV}, 5 \mu \mathrm{A}, 10 \mathrm{~min})$ and annealing in $\mathrm{O}_{2}$ gas $\left(1000^{\circ} \mathrm{C}\right.$, $3 \times 10^{-6}$ mbar, $1 \mathrm{~h}$ ), to remove contamination. The surface of each sample was then prepared to exhibit predominantly a $(4 \times 1)$ or a $(2 \times 5)$ structure. The $(4 \times 1)$ structure was obtained by deposition of sub-monolayer amounts of $\mathrm{Sr}$ or $\mathrm{Ti}$ at room temperature, and subsequent annealing in an $\mathrm{O}_{2}$ background $\left(1000^{\circ} \mathrm{C}\right.$, $3 \times 10^{-6}$ mbar, $\left.30 \mathrm{~min}\right)^{35}$. Particular care was taken in obtaining a uniform structure over the whole sample surface, by deposition of small amounts of metals while partly shadowing the sample with a dedicated shutter. The $(2 \times 5)$ reconstructed surfaces were obtained by reactively depositing $\left(5 \times 10^{-6} \mathrm{mbar}_{2}\right)$ $0.8 \AA \mathrm{Ti}$ at $600{ }^{\circ} \mathrm{C}$ on $\mathrm{SrTiO}_{3}(110)-(4 \times 1)$. Two sets of samples were prepared: either single-phase [uniformly $(4 \times 1)$ - or $(2 \times 5)$-reconstructed on a given crystal], to allow for STM characterization, or with both the $(4 \times 1)$ and $(2 \times 5)$ co-existing on the same crystal surface, each occupying $\sim 5 \times 2.5 \mathrm{~mm}^{2}$. In the latter case, half of the sample surface was shadowed during reactive deposition of Ti to induce the $(2 \times 5)$ surface after the $(4 \times 1)$ surface was formed. We refer to the latter as a "surface bi-crystal." The results obtained with the two sets of samples were checked for consistency by comparing the LEED patterns on several spots on the sample at each preparation step, and after the subsequent treatments.

${ }^{18} \mathrm{O}$ isotope exchange. To ensure the stabilization of a steady-state oxygen vacancy $\left(\mathrm{V}_{\mathrm{O}}\right)$ concentration, the as-prepared samples were first annealed in situ in flowing $\mathrm{O}_{2}$ gas of natural isotope composition (referred to as ${ }^{16} \mathrm{O}_{2}$ ) for $4 \mathrm{~h}$ or $16 \mathrm{~h}$

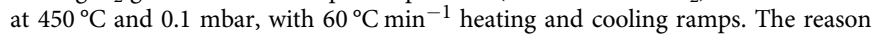
for performing the exchange at a relatively low temperature and oxygen pressure is 
to minimize the risk of atomic surface structure changes. Furthermore, because of the very low vacancy concentration (as explained above), the $\mathrm{O}_{2}$ exchange is expected to be limited to the near-surface region without bulk transport. Prior to the equilibration step, the vessel was continuously flushed with ${ }^{16} \mathrm{O}_{2}(20 \mathrm{sccm})$ for $1 \mathrm{~h}$; this ensures reproducible conditions in the vacuum chamber. The pumping speed was regulated to stabilize a pressure of 1 mbar. Finally, each sample was annealed in isotopically labeled oxygen $\left(97.1 \%{ }^{18} \mathrm{O}_{2}\right.$, referred to as ${ }^{18} \mathrm{O}_{2}$ for brevity) for $1 \mathrm{~h}$ or $4 \mathrm{~h}$, at $450^{\circ} \mathrm{C}$ and $0.1 \mathrm{mbar}$ (static) with heating and cooling ramps of 60 ${ }^{\circ} \mathrm{C} \mathrm{min}^{-1}$ and $120^{\circ} \mathrm{C} \mathrm{min}^{-1}$, respectively. Similar to the ${ }^{16} \mathrm{O}_{2}$ equilibration step, the chamber was pre-conditioned in ${ }^{18} \mathrm{O}_{2}$ at $0.5 \mathrm{mbar}$ static pressure for $30 \mathrm{~min}$ prior to each experiment. After the ${ }^{18} \mathrm{O}_{2}$ treatments, samples were analyzed with LEED, XPS (both monophase and surface bi-crystal samples), STM, and LEIS (monophase samples only) in situ, i.e., in the UHV apparatus, and then transported to the timeof-flight-secondary-ion mass spectrometry (ToF-SIMS) setup.

Depth profiling and quantification of ${ }^{\mathbf{1 8}} \mathbf{0}$. Oxygen-isotope depth profiles were analyzed via ToF-SIMS on a TOF-SIMS 5 instrument (ION-TOF, Germany). $25 \mathrm{keV} \mathrm{Bi}{ }_{3}{ }^{++}$clusters $(0.02 \mathrm{pA})$ were used as primary ions in collimated burst alignment mode optimized for oxygen isotope measurements ${ }^{18,48}$. Negative secondary ions were detected from areas of $100 \times 100 \mu \mathrm{m}^{2}$ using a raster of $512 \times 512$ measured points, and the secondary ion counts of ${ }^{16} \mathrm{O}^{-}$and ${ }^{18} \mathrm{O}^{-}$were used to determine the isotopic composition $f={ }^{18} \mathrm{O} /\left({ }^{18} \mathrm{O}+{ }^{16} \mathrm{O}\right)$. For depth profiling, areas of $400 \times 400 \mathrm{\mu m}^{2}$ were sputtered using $\mathrm{Cs}^{+}$ions, and the depth information was calculated from the sputter coefficients and sputter currents, referenced by measuring the depth of the sputter craters via digital holography microscopy. An electron flood gun $(21 \mathrm{eV})$ was used for charge compensation.

For calculating the average oxygen exchange coefficient $k^{\star}$ from the measured fraction of incorporated ${ }^{18} \mathrm{O}\left(f_{\mathrm{m}}\right)$, the ${ }^{18} \mathrm{O}$ fraction in the stainless steel UHV vessel $\left(f_{\text {out }}\right)$ was estimated as 0.971 , corresponding to the original ${ }^{18} \mathrm{O}$ concentration of the tracer-enriched oxygen. The validity of this assumption was tested by exchanging $\left(\text { at } 700^{\circ} \mathrm{C}\right)^{18} \mathrm{O}$ into a fast-mixed ionic electronic conductor, a $50 \mathrm{~nm}$ thick $\mathrm{La}_{0.6} \mathrm{Sr}_{0.4} \mathrm{CoO}_{3}$ film grown on $\mathrm{SrTiO}_{3}(001)^{40}$, under nominally identical gas composition as the exchange experiment performed on the $\mathrm{SrTiO}_{3}(110)$ crystals in the same UHV setup. Since $f_{\text {out }}$ is much larger than all tracer fractions measured in the $\mathrm{Nb}$-doped $\mathrm{SrTiO}_{3}$ single crystals, we can approximately assume a constant tracer exchange flux density $j$ during the exchange time $t$. Within this assumption, the effective oxygen exchange coefficient can be expressed as (see Supplementary Note 2 for the full derivation)

$$
k^{*}=\frac{j}{\left(f_{\text {out }}-f_{\mathrm{bg}}\right) c_{O}}=\frac{\sum_{\text {meas points }}\left(f_{m}-f_{\mathrm{bg}}\right) d_{\mathrm{s}} / t}{\left(f_{\text {out }}-f_{\mathrm{bg}}\right)} .
$$

In Eq. (1), $f_{\mathrm{bg}}$ denotes the background tracer fraction (approximated by the natural abundance $\left.f_{\mathrm{bg}}=0.00205\right), c_{\mathrm{O}}$ is the concentration of oxygen sites, and $d_{\mathrm{s}}$ is the sputter depth per measurement point.

First-principles calculations. All calculations were carried out using the Vienna $\mathrm{ab}$ initio simulation package (VASP) ${ }^{49,50}$ in the framework of density functional theory (DFT) within the generalized gradient correction approximation of Perdew, Burke and Ernzerhof ${ }^{51}$. The surface reconstructions were modeled with symmetric slabs composed by five layers plus the reconstructed surfaces, separated by $\sim 12 \AA$ of vacuum. We used the same $(4 \times 4)$ two-dimensional base unit cell for both types of $\mathrm{SrTiO}_{3}(110)$ reconstructions, effectively modeling $(4 \times 2)$ and $(2 \times 4)$ reconstructions. $(4 \times 2)$ and $(4 \times 1)$ belong to the same $(n \times 1)$ structure family, and $(2 \times 4)$ and $(2 \times 5)$ belong to the same $(2 \times n)$ surface structure family. For consistency with the experimental description, we refer to the slabs representing the $(n \times 1)$ overlayer as $(4 \times 1)$, and the $(2 \times n)$ overlayer as $(2 \times 5)$ in the text. The surface geometry was optimized by keeping the central three layers fixed to the corresponding bulk positions and relaxing the remaining atomic positions until the forces on each atom were less than $0.02 \mathrm{eV} \AA^{-1}$. For the Brillouin-zone integration, we have adopted a $2 \times 2 \times 1 \mathrm{k}$-point grid, corresponding to an $8 \times 8 \times 1$ mesh for the $1 \times 1$ cell, and used a standard energy cutoff of about $300 \mathrm{eV}$ for the plane-wave expansion. The formation energy of one oxygen vacancy formed on both sides of the symmetric slab was computed using the standard relation

$$
E_{\mathrm{f}}\left(\mathrm{V}_{\mathrm{O}}\right)=\frac{1}{2}\left[E_{\text {tot }}\left(2 \mathrm{~V}_{\mathrm{O}}\right)+E_{\mathrm{O}_{2}}^{\mathrm{mol}}-E_{\text {tot }}\left(0 \mathrm{~V}_{\mathrm{O}}\right)\right]
$$

where $E_{\mathrm{O}_{2}}^{\mathrm{mol}}$ is the DFT energy of an isolated oxygen molecule, whereas $E_{\text {tot }}\left(2 \mathrm{~V}_{\mathrm{O}}\right)$ and $E_{\text {tot }}\left(0 \mathrm{~V}_{\mathrm{O}}\right)$ represent the DFT total energies of the slabs with and without oxygen vacancies, respectively.

The interaction between the surfaces and oxygen atoms was modeled by studying the adsorption, dissociation, and dynamics of one $\mathrm{O}_{2}$ molecule by means of first-principles molecular dynamics (FPMD) and the climbing image nudged elastic band (CI-NEB) ${ }^{52}$. To reduce the computational costs, the FPMD and CINEB calculations were performed using asymmetric slabs with a reduced energy cutoff $(250 \mathrm{eV})$ and a smaller $\mathbf{k}$-mesh $(1 \times 1)$. The FPMD calculations were performed at the simulating temperature of $700 \mathrm{~K}$ for $5-10$ ps using a canonical ensemble and the Nosé thermostat algorithm ${ }^{53}$. For the estimation of energy barriers within the CI-NEB method, five images were constructed, and the convergence criteria for the forces was reduced to $0.05 \mathrm{eV} \AA^{-1}$.
Relative adsorption energies $E_{\text {ads }}$ per $\mathrm{O}_{2}$ molecule, as given in the text, are defined as $E_{\text {ads }}=E_{\text {slab }}-E_{\text {clean }}-E_{\mathrm{O}_{2}}^{\text {mol }}+x E_{\mathrm{V}_{\mathrm{o}}}$, where $E_{\text {slab }}$ and $E_{\text {clean }}$ are the $T=0$ DFT total energies of the full slab containing the $\mathrm{O}_{2}$ molecule and the clean surface, respectively. $E_{\mathrm{V}_{\mathrm{os}}}$ refers to the oxygen vacancy formation energy at site $\mathrm{S}$, chosen as the energetically least costly $\mathrm{V}_{\mathrm{O} 3}$ and $\mathrm{V}_{\mathrm{O} 4}$ for the $(4 \times 1)$ and $(2 \times 5)$-like surfaces, respectively (see Supplementary Note 7), and $x$ indicates the number of oxygen vacancies in the slab.

Work functions were computed as the difference between the Fermi energy (valence band maximum) and the vacuum level, extracted from the local potential profile in the direction perpendicular to the slab.

\section{Data availability}

The data that support the findings of this study are available from the authors on reasonable request. Source data for Figs. 1 and 4, and Supplementary Figs. 7, 9, and 10 are provided with the paper in Supplementary Data 1.

Received: 13 June 2018 Accepted: 22 July 2018

Published online: 13 September 2018

\section{References}

1. Neagu, D., Tsekouras, G., Miller, D. N., Ménard, H. \& Irvine, J. T. S. In situ growth of nanoparticles through control of non-stoichiometry. Nat. Chem. 5, 916-923 (2013).

2. Lee, K. T. \& Wachsman, E. D. Role of nanostructures on SOFC performance at reduced temperatures. MRS Bull. 39, 783-791 (2014).

3. Fleig, J. Solid oxide fuel cell cathodes: polarization mechanisms and modeling of the electrochemical performance. Annu. Rev. Mater. Res. 33, 361-382 (2003).

4. Graves, C., Ebbesen, S. D., Jensen, S. H., Simonsen, S. B. \& Mogensen, M. B. Eliminating degradation in solid oxide electrochemical cells by reversible operation. Nat. Mater. 14, 239-244 (2015).

5. Chueh, W. C. et al. High-flux solar-driven thermochemical dissociation of $\mathrm{CO}_{2}$ and $\mathrm{H}_{2} \mathrm{O}$ using nonstoichiometric ceria. Science 330, 1797-1801 (2010).

6. Kuklja, M. M., Kotomin, E. A., Merkle, R., Mastrikov, Y. A. \& Maier, J. Combined theoretical and experimental analysis of processes determining cathode performance in solid oxide fuel cells. Phys. Chem. Chem. Phys. 15, 5443-5471 (2013).

7. Bikondoa, O. et al. Direct visualization of defect-mediated dissociation of water on $\mathrm{TiO}_{2}(110)$. Nat. Mater. 5, 189-192 (2006).

8. Diebold, U. The surface science of titanium dioxide. Surf. Sci. Rep. 48, 53-229 (2003).

9. Schaub, R. et al. Oxygen vacancies as active sites for water dissociation on rutile $\mathrm{TiO}_{2}$ (110). Phys. Rev. Lett. 87, 266104 (2001).

10. Scheiber, P., Riss, A., Schmid, M., Varga, P. \& Diebold, U. Observation and destruction of an elusive adsorbate with STM: $\mathrm{O}_{2} / \mathrm{TiO}_{2}(110)$. Phys. Rev. Lett. 105, 216101 (2010).

11. Deskins, N. A., Rousseau, R. \& Dupuis, M. Defining the role of excess electrons in the surface chemistry of $\mathrm{TiO}_{2}$. J. Phys. Chem. C 114, 5891-5897 (2010).

12. Greiner, M. T. et al. Universal energy-level alignment of molecules on metal oxides. Nat. Mater. 11, 76-81 (2012).

13. Greiner, M. T., Chai, L., Helander, M. G., Tang, W.-M. \& Lu, Z.-H. Transition metal oxide work functions: the influence of cation oxidation state and oxygen vacancies. Adv. Funct. Mater. 22, 4557-4568 (2012).

14. Chen, Y. et al. Electronic activation of cathode superlattices at elevated temperatures - source of markedly accelerated oxygen reduction kinetics. $A d v$. Energy Mater. 3, 1221-1229 (2013).

15. Merkle, R. \& Maier, J. Oxygen incorporation into Fe-doped $\mathrm{SrTiO}_{3}$ : mechanistic interpretation of the surface reaction. Phys. Chem. Chem. Phys. 4, 4140-4148 (2002).

16. Lee, Y.-L., Kleis, J., Rossmeisl, J., Shao-Horn, Y. \& Morgan, D. Prediction of solid oxide fuel cell cathode activity with first-principles descriptors. Energy Environ. Sci. 4, 3966-3970 (2011).

17. Brichzin, V., Fleig, J., Habermeier, H.-U., Cristiani, G. \& Maier, J. The geometry dependence of the polarization resistance of Sr-doped $\mathrm{LaMnO}_{3}$ microelectrodes on yttria-stabilized zirconia. Solid State Ion. 152-153, 499-507 (2002).

18. Kubicek, M. et al. A novel ToF-SIMS operation mode for sub $100 \mathrm{~nm}$ lateral resolution: application and performance. Appl. Surf. Sci. 289, 407-416 (2014).

19. Yan, L., Balasubramaniam, K. R., Wang, S., Du, H. \& Salvador, P. A. Effects of crystallographic orientation on the oxygen exchange rate of $\mathrm{La}_{0.7} \mathrm{Sr}_{0.3} \mathrm{MnO}_{3}$ thin films. Solid State Ion. 194, 9-16 (2011).

20. Burriel, $M$. et al. Influence of crystal orientation and annealing on the oxygen diffusion and surface exchange of $\mathrm{La}_{2} \mathrm{NiO}_{4+\delta}$. J. Phys. Chem. C 120, 17927-17938 (2016). 
21. Chang, S. H. et al. Functional links between stability and reactivity of strontium ruthenate single crystals during oxygen evolution. Nat. Commun. 5, 4191 (2014).

22. Kerman, K., Ko, C. \& Ramanathan, S. Orientation dependent oxygen exchange kinetics on single crystal $\mathrm{SrTiO}_{3}$ surfaces. Phys. Chem. Chem. Phys. 14, 11953-11960 (2012).

23. Hayd, J., Yokokawa, H. \& Ivers-Tiffée, E. Hetero-interfaces at nanoscaled (La, $\mathrm{Sr}) \mathrm{CoO}_{3-\delta}$ thin-film cathodes enhancing oxygen surface-exchange properties. J. Electrochem. Soc. 160, F351-F359 (2013).

24. Carter, S. et al. Oxygen-transport in selected nonstoichiometric perovskitestructure oxides. Solid State Ion. 53-56, 597-605 (1992).

25. Shao, Z. \& Haile, S. M. A high-performance cathode for the next generation of solid-oxide fuel cells. Nature 431, 170-173 (2004).

26. Cai, Z., Kubicek, M., Fleig, J. \& Yildiz, B. Chemical heterogeneities on $\mathrm{La}_{0.6} \mathrm{Sr}_{0.4} \mathrm{CoO}_{3-\delta}$ thin films-correlations to cathode surface activity and stability. Chem. Mater. 24, 1116-1127 (2012).

27. Lee, W., Han, J. W., Chen, Y., Cai, Z. \& Yildiz, B. Cation size mismatch and charge interactions drive dopant segregation at the surfaces of manganite perovskites. J. Am. Chem. Soc. 135, 7909-7925 (2013).

28. Chen, Y. et al. Segregated chemistry and structure on (001) and (100) surfaces of $\left(\mathrm{La}_{1-x} \mathrm{Sr}_{x}\right)_{2} \mathrm{CoO}_{4}$ override the crystal anisotropy in oxygen exchange kinetics. Chem. Mater. 27, 5436-5450 (2015).

29. Téllez, H., Druce, J., Ju, Y.-W., Kilner, J. \& Ishihara, T. Surface chemistry evolution in $\mathrm{LnBaCo}_{2} \mathrm{O}_{5+\delta}$ double perovskites for oxygen electrodes. Int. J. Hydrog. Energy 39, 20856-20863 (2014).

30. Chen, Y. et al. Impact of Sr segregation on the electronic structure and oxygen reduction activity of $\mathrm{SrTi}_{1-x} \mathrm{Fe}_{x} \mathrm{O}_{3}$ surfaces. Energy Environ. Sci. 5, 7979-7988 (2012).

31. Wang, Z. et al. Transition from reconstruction toward thin film on the (110) surface of strontium titanate. Nano Lett. 16, 2407-2412 (2016).

32. Ohsawa, T., Shimizu, R., Iwaya, K., Shiraki, S. \& Hitosugi, T. Negligible Sr segregation on $\mathrm{SrTiO}_{3}(001)-(\sqrt{ } 13 \times \sqrt{ } 13)-R 33.7^{\circ}$ reconstructed surfaces. Appl. Phys. Lett. 108, 161603 (2016).

33. Heifets, E., Piskunov, S., Kotomin, E. A., Zhukovskii, Y. F. \& Ellis, D. E. Electronic structure and thermodynamic stability of double-layered $\mathrm{SrTiO}_{3}(001)$ surfaces: ab initio simulations. Phys. Rev. B 75, 115417 (2007)

34. Wang, Z. et al. Strain-induced defect superstructure on the $\mathrm{SrTiO}_{3}(110)$ surface. Phys. Rev. Lett. 111, 056101 (2013).

35. Wang, Z. et al. Evolution of the surface structures on $\mathrm{SrTiO}_{3}(110)$ tuned by Ti or Sr concentration. Phys. Rev. B 83, 155453 (2011).

36. Sugiura, $\mathrm{S}$. et al. Role of oxygen vacancy in dissociation of oxygen molecule on SOFC cathode: Ab initio molecular dynamics simulation. Solid State Ion. 285, 209-214 (2016).

37. Li, X. \& Benedek, N. A. Enhancement of ionic transport in complex oxides through soft lattice modes and epitaxial strain. Chem. Mater. 27, 2647-2652 (2015).

38. Wang, Z. et al. Anisotropic two-dimensional electron gas at $\mathrm{SrTiO}_{3}(110)$. Proc. Natl. Acad. Sci. USA 111, 3933-3937 (2014).

39. Gong, X.-Q., Selloni, A., Batzill, M. \& Diebold, U. Steps on anatase $\mathrm{TiO}_{2}(101)$. Nat. Mater. 5, 665-670 (2006).

40. Kubicek, M. et al. Tensile lattice strain accelerates oxygen surface exchange and diffusion in $\mathrm{La}_{1-x} \mathrm{Sr}_{x} \mathrm{CoO}_{3-\delta}$ thin films. ACS Nano 7, 3276-3286 (2013).

41. Kubicek, M., Limbeck, A., Frömling, T., Hutter, H. \& Fleig, J. Relationship between cation segregation and the electrochemical oxygen reduction kinetics of $\mathrm{La}_{0.6} \mathrm{Sr}_{0.4} \mathrm{CoO}_{3-\delta}$ thin film electrodes. J. Electrochem. Soc. 158, B727-B734 (2011).

42. Tsvetkov, N., Lu, Q., Sun, L., Crumlin, E. J. \& Yildiz, B. Improved chemical and electrochemical stability of perovskite oxides with less reducible cations at the surface. Nat. Mater. 15, 1010-1016 (2016).

43. Rupp, G. M. et al. Correlating surface cation composition and thin film microstructure with the electrochemical performance of lanthanum strontium cobaltite (LSC) electrodes. J. Mater. Chem. A 2, 7099-7108 (2014).

44. Erdman, N. et al. The structure and chemistry of the $\mathrm{TiO}_{2}$-rich surface of $\mathrm{SrTiO}_{3}(001)$. Nature 419, 55-58 (2002).

45. Lu, Q. \& Yildiz, B. Voltage-controlled topotactic phase transition in thin-film $\mathrm{SrCoO}_{x}$ monitored by in situ x-ray diffraction. Nano Lett. 16, 1186-1193 (2016).

46. Nyholm, R. S., Woolliams, P. R., Shepard, D., Guyer, J. \& Cohn, K. in Inorganic Syntheses Vol. 11 (ed. Jolly, W. L.) 56-61 (John Wiley \& Sons, Inc., Hoboken, NJ, USA, 1968).
47. Gerhold, S., Riva, M., Yildiz, B., Schmid, M. \& Diebold, U. Adjusting island density and morphology of the $\mathrm{SrTiO}_{3}(110)-(4 \times 1)$ surface: pulsed laser deposition combined with scanning tunneling microscopy. Surf. Sci. 651, 76-83 (2016)

48. Holzlechner, G., Kubicek, M., Hutter, H. \& Fleig, J. A novel ToF-SIMS operation mode for improved accuracy and lateral resolution of oxygen isotope measurements on oxides. J. Anal. At. Spectrom. 28, 1080-1089 (2013).

49. Kresse, G., \& Hafner, J. Ab initio molecular dynamics for open-shell transition metals. Phys. Rev. B 48, 13115-13118 (1993).

50. Kresse, G., \& Furthmüller, J. Efficiency of $a b$-initio total energy calculations for metals and semiconductors using a plane-wave basis set. Comput. Mater. Sci. 6, 15-50 (1996).

51. Perdew, J. P., Burke, K. \& Ernzerhof, M. Generalized gradient approximation made simple. Phys. Rev. Lett. 77, 3865-3868 (1996).

52. Henkelman, G., Uberuaga, B. P. \& Jónsson, H. A climbing image nudged elastic band method for finding saddle points and minimum energy paths. $J$. Chem. Phys. 113, 9901-9904 (2000).

53. Nosé, S. A unified formulation of the constant temperature molecular dynamics methods. J. Chem. Phys. 81, 511-519 (1984).

\section{Acknowledgements}

This work was supported by the Austrian Science Fund FWF (SFB "Functional Oxide Surfaces and Interfaces" - FOXSI, Project F 45) and by the ERC Advanced Grant "OxideSurfaces" (Project ERC-2011-ADG_20110209). B.Y. also thanks for support from the NSF CAREER Award of the National Science Foundation, Division of Materials Research, Ceramics Program, Grant No. 1055583. C.F. acknowledges the support of the FWF-SFB project ViCoM (Grant No. F41). X.H. thanks National Natural Science Foundation of China (Grant Nos. 21303156 and 21543006) for support. The computational results presented have been achieved using the Vienna Scientific Cluster (VSC).

\section{Author contributions}

M.R., G.F., and S.G. prepared the samples and performed the STM, XPS, WF, LEED, LEIS, and exchange experiment. M.K., H.H., and J.F. performed and analyzed the ${ }^{18} \mathrm{O}$ SIMS. C.F. and X.H. performed the DFT calculations. M.R., M.K., M.S., J.F., C.F., B.Y., and U.D. wrote the manuscript. J.F., U.D., B.Y., and M.S. designed and coordinated the research.

\section{Additional information}

Supplementary Information accompanies this paper at https://doi.org/10.1038/s41467018-05685-5.

Competing interests: The authors declare no competing interests.

Reprints and permission information is available online at http://npg.nature.com/ reprintsandpermissions/

Publisher's note: Springer Nature remains neutral with regard to jurisdictional claims in published maps and institutional affiliations.

Open Access This article is licensed under a Creative Commons Attribution 4.0 International License, which permits use, sharing, adaptation, distribution and reproduction in any medium or format, as long as you give appropriate credit to the original author(s) and the source, provide a link to the Creative Commons license, and indicate if changes were made. The images or other third party material in this article are included in the article's Creative Commons license, unless indicated otherwise in a credit line to the material. If material is not included in the article's Creative Commons license and your intended use is not permitted by statutory regulation or exceeds the permitted use, you will need to obtain permission directly from the copyright holder. To view a copy of this license, visit http://creativecommons.org/ licenses/by/4.0\%.

(C) The Author(s) 2018 